OPEN ACCESS

Edited by:

Sutthirat Sitthisak

Naresuan University, Thailand

Reviewed by:

Shuguang Lu,

Third Military Medical University,

China

Elina Roine

University of Helsinki, Finland

${ }^{*}$ Correspondence:

Meng-Jiun Lai

monjou@mail.tcu.edu.tw

Kai-Chih Chang

kaichih@mail.tcu.edu.tw

${ }^{\dagger}$ These authors have contributed equally to this work

Specialty section This article was submitted to Antimicrobials, Resistance and Chemotherapy

a section of the journal Frontiers in Microbiology

Received: 29 November 2019 Accepted: 27 March 2020 Published: 13 May 2020

Citation:

Peng S-Y, Chen L-K, Wu W-J, Paramita P, Yang P-W, Li Y-Z, Lai M-J and Chang K-C (2020) Isolation and

Characterization of a New Phage Infecting Elizabethkingia anophelis and Evaluation of Its Therapeutic

Efficacy in vitro and in vivo.

Front. Microbiol. 11:728.

doi: 10.3389/fmicb.2020.00728

\section{Isolation and Characterization of a} New Phage Infecting Elizabethkingia anophelis and Evaluation of Its Therapeutic Efficacy in vitro and in vivo

\author{
Shih-Yi Peng ${ }^{1,2 t}$, Li-Kuang Chen ${ }^{3 \dagger}$, Wen-Jui Wu' ${ }^{1}$, Prajna Paramita ${ }^{1}$, Po-Wei Yang', \\ Yun-Zhong Li ${ }^{3}$, Meng-Jiun Lai ${ }^{1 *}$ and Kai-Chih Chang ${ }^{1,4 *}$
}

'Department of Laboratory Medicine and Biotechnology, Tzu Chi University, Hualien, Taiwan, ${ }^{2}$ Department of Biochemistry, Tzu Chi University, Hualien, Taiwan, ${ }^{3}$ Department of Clinic Pathology, Buddhist Tzu Chi General Hospital, Hualien, Taiwan,

${ }^{4}$ Department of Laboratory Medicine, Buddhist Tzu Chi General Hospital, Hualien, Taiwan

Elizabethkingia spp. are a group of non-fermentative, Gram-negative, catalase-positive, and non-motile bacilli. They can cause meningitis in neonates and immunosuppressed patients, and lead to high mortality. Considering the rising trend of drug resistance among bacteria pathogens, bacteriophage (phage) therapy is a potential alternative to antibiotics for treating multidrug-resistant bacterial infections. However, so far, no phages specific for Elizabethkingia spp. have been reported. Using a clinically isolated Elizabethkingia anophelis as the host, the phage TCUEAP1 was isolated from wastewater of Hualien Tzu Chi hospital. The phage particle of TCUEAP1 under electron microscopy was revealed to belong to the siphoviridae family, with a head size of $47 \mathrm{~nm}$, and a tail dimension $12 \mathrm{~nm}$ in diameter and $172 \mathrm{~nm}$ in length. The one-step growth analysis showed that the latent period of TCUEAP1 was about 40 min with a rise period lasting about $20 \mathrm{~min}$, yielding a burst size of approximately $10 \mathrm{PFU} / \mathrm{cell}$. The adsorption rate of TCUEAP1 reached about $70 \%$ in 20 min. Using 20 isolates of Elizabethkingia spp. to test the host range of TCUEAP1, it displayed narrow spectrum infecting three strains of $E$. anophelis, but forming spot lysis on 16 strains. The sequence result showed that the genome of TCUEAP1 is a double-stranded DNA of 49,816 bp, containing 73 predicted open reading frames. Further genomic analysis showed TCUEAP1 to be a new phage with no resemblance to publicly available phage genomes. Finally, in a mouse intraperitoneal infection model, at $6 \mathrm{~h}$ after the bacterial injection, TCUEAP1 decreased the bacterial load by fivefold in blood. Also, TCUEAP1 rescued $80 \%$ of mice heavily infected with $E$. anophelis from lethal bacteremia. We hope that the isolation and characterization of TCUEAP1, the first phage infecting Elizabethkingia spp., can promote more studies of the phages targeting this newly emerging bacterial pathogen. 


\section{INTRODUCTION}

The genus Elizabethkingia comprises Gram-negative, nonfermenting, non-motile, obligate aerobic bacteria in the family Flavobacteriaceae. This genus was originally designated Flavobacterium meningoseptica by King (1959). It was subsequently reclassified into the genus Chryseobacterium in 1994 (Vandamme et al., 1994). In 2005, based mainly on $16 \mathrm{~S}$ rRNA gene sequencing, it was moved to the new genus Elizabethkingia (Kim et al., 2005). Genome mapping has enabled further identification of species belonging to this genus, including the E. meningoseptica, Elizabethkingia anophelis, and E. miricola cluster. Notably, accumulating evidence indicates that what previously have been identified as E. meningoseptica strains causing sporadic cases of meningitis and bacteremia are actually E. anophelis (Coyle, 2017; Han et al., 2017).

Elizabethkingia anophelis has been reported to cause neonatal meningitis (Frank et al., 2013), bacteremia (Lau et al., 2016), and nosocomial outbreaks (Teo et al., 2013). Most studies investigating the antimicrobial resistance of E. meningoseptica were performed before the proposal of E. anophelis; therefore, these studies may actually represent the antimicrobial susceptibility patterns of all Elizabethkingia species, particularly E. anophelis. Several studies applied reliable species identification methods, and have demonstrated that $E$. anophelis isolates were resistant to most $\beta$-lactams, $\beta$-lactam/ $\beta$-lactam inhibitor combinations, carbapenems, and aminoglycosides (Perrin et al., 2017; Lin et al., 2018, 2019; Cheng et al., 2019). A wide variation exists in the susceptibility of E. anophelis to piperacillin, piperacillin-tazobactam, ciprofloxacin, levofloxacin, trimethoprim-sulfamethoxazole, and vancomycin (Lin et al., 2019). The treatment options for E. anophelis infections are becoming increasingly limited (Janda and Lopez, 2017). For these reasons, there is an urgent need to develop new antibacterial agents to combat the infections caused by Elizabethkingia species.

Bacteriophages (phages) are attractive alternatives to antibiotics for treating bacterial infections (Caflisch and Patel, 2019). They have a low environmental impact compared to chemical antibiotics due to their natural origin (Wittebole et al., 2014). They target both Gram-positive and Gramnegative bacteria, and many in vitro and in vivo models have shown that phages are effective against multidrug-resistant bacteria (Schooley et al., 2017; Dedrick et al., 2019). As antibiotic resistance grows, phages retain the ability to kill antibiotic-resistant bacteria due to their differing mechanisms of action (Abedon et al., 2017). They are highly specific, lysing only their bacterial hosts, and are auto "dosing" in that phage replication at the site of infection, leading to marked increases in their titer (Merril et al., 2003; Abedon et al., 2017). So far, there are no reports of isolation of the phages infecting Elizabethkingia species. In this study, we present the isolation and characterization of the world's first strain of the virulent phage against $E$. anophelis, termed TCUEAP1, from the wastewater of Hualien Tzu Chi hospital. The in vitro and in vivo therapeutic efficacy of phage TCUEAP1 was also evaluated.

\section{MATERIALS AND METHODS}

\section{Bacterial Strains and Growth Conditions}

The bacteria used in this study are summarized in Table 1. Among the 20 strains of the Elizabethkingia species, the reference strain of E. meningoseptica was obtained from the Bioresource Collection and Research Center (BCRC), and the other 19 nonrepetitive isolates were collected from two branches (Hualien and Taipei) of the Buddhist Tzu Chi General Hospital in Taiwan. The species were initially identified using the Vitek 2 compact system (Biomerieux, France). Further differentiation of these isolates as E. meningoseptica or E. anophelis was performed using PCR, based on the method described by Chew et al. (2018). When isolates could not be identified as E. meningoseptica or E. anophelis by PCR, sequencing of the 16S rRNA gene was used as the reference standard for species identification (Chang et al., 2014). To analyze the homology of the collected strains, pulsed-field gel electrophoresis (PFGE) was performed (Chang et al., 2014). Bacteria were cultivated in Luria Bertani (LB) broth or LB agar (BioShop Canada Inc., Burlington) at 25 or $37^{\circ} \mathrm{C}$. The growth of bacteria was monitored by measuring the optical density at $600 \mathrm{~nm}\left(\mathrm{OD}_{600}\right)$, where an $\mathrm{OD}$ unit of 1.0 corresponded to $1 \times 10^{9}$ cells $/ \mathrm{ml}$.

\section{Isolation and Purification of Bacteriophage}

All the wastewater samples were collected in Hualien Tzu Chi hospital and were used for screening phages specific to the isolated Elizabethkingia strains. Thirty milliliters of wastewater samples were centrifuged at $10,000 \times g$ for $10 \mathrm{~min}$ to clear bacteria and debris, and filtered through a $0.22-\mu \mathrm{m}$ Millipore filter. To enrich the phages in the wastewater samples, each time $25 \mathrm{ml}$ of filtrate was mixed with $500 \mu \mathrm{l}$ of bacterial solution consisting of five Elizabethkingia strains $\left(10^{8} \mathrm{CFU}\right.$ each) all in log-phase and incubated at $37^{\circ} \mathrm{C}$ for $4 \mathrm{~h}$. In total, 20 strains were used for the enrichment procedure. After the enrichment period, the mixtures were centrifuged at $10,000 \times g$ for $10 \mathrm{~min}$ and filtered through $0.22-\mu \mathrm{m}$ Millipore filters. For each tested bacterial strain, $1 \mathrm{ml}$ of the filtrate was mixed with $100 \mu \mathrm{l}$ of bacteria culture $\left(10^{8} \mathrm{CFU}\right)$ in log phase. The mixture was added to $5 \mathrm{ml}$ of soft LB agar $(0.7 \%)$ and then poured over solidified $\mathrm{LB}$ agar plates. The plates were incubated overnight at $25^{\circ} \mathrm{C}$. For the enriched samples showing inhibited bacterial growth, the clear zone of the single plaque was picked using a sterile Pasteur pipette tip, and propagated in a new culture. The new mixture was serially diluted and plated on soft agar medium (0.7\%) again for plaque formation. This procedure was repeated three times for phage purification.

\section{Phage Purification}

Lysates for TCUEAP1 phage purification were prepared by infecting $200 \mathrm{ml}$ of E. anophelis ANO15 in early log-phase with TCUEAP1 at a multiplicity of infection (MOI) of about 1.0, and incubating with aeration for $4 \mathrm{~h}$. Crude lysates were centrifuged and the supernatants were passed through a membrane filter with a pore size of $0.45 \mu \mathrm{m}$. The phage particles were concentrated by 
TABLE 1 | Bacterial strains used to screen the phages from wastewater and to perform the host range analysis of TCUEAP1.

\begin{tabular}{|c|c|c|c|c|}
\hline No. & Bacterial strain & Plaque formation ${ }^{a}$ & TCUEAP1 spot test ${ }^{b}$ & Source \\
\hline \multicolumn{5}{|c|}{ E. meningoseptica } \\
\hline 1 & E. meningoseptica BCRC 10677 & - & $\mathrm{N}$ & BCRC \\
\hline 2 & E. meningoseptica MEN1 & - & $P$ & Clinical isolate from Buddhist Tzu Chi General Hospital (BTCGH), Hualien \\
\hline \multicolumn{5}{|c|}{ E. anophelis } \\
\hline 3 & E. anophelis ANO1 & - & $\mathrm{P}$ & Clinical isolates from BTCGH, Hualien \\
\hline 4 & E. anophelis ANO2 & - & $P$ & \\
\hline 5 & E. anophelis ANO3 & - & $P$ & \\
\hline 6 & E. anophelis ANO5 & - & $\mathrm{P}$ & \\
\hline 7 & E. anophelis ANO9 & - & $P$ & \\
\hline 8 & E. anophelis ANO10 & + & $\mathrm{P}$ & \\
\hline 9 & E. anophelis ANO12 & + & $P$ & \\
\hline 10 & E. anophelis ANO13 & - & $P$ & \\
\hline 11 & E. anophelis ANO14 & - & $P$ & \\
\hline 12 & E. anophelis ANO15 & + & $P$ & \\
\hline 13 & E. anophelis ANO16 & - & $\mathrm{N}$ & \\
\hline 14 & E. anophelis ANO17 & - & $\mathrm{P}$ & \\
\hline 15 & E. anophelis ANO18 & - & $P$ & \\
\hline 16 & E. anophelis ANO19 & - & $P$ & Clinical isolate from BTCGH, Taipei \\
\hline 17 & E. anophelis ANO20 & - & $P$ & \\
\hline 18 & E. anopheliseANO21 & - & $P$ & \\
\hline \multicolumn{5}{|c|}{ E. miricola } \\
\hline 19 & E. miricola MIR1 & - & $\mathrm{N}$ & Clinical isolates from BTCGH, Taipei \\
\hline 20 & E. miricola MIR2 & - & $\mathrm{N}$ & \\
\hline
\end{tabular}

${ }^{+}$, susceptibility to TCUEAP1; -, no susceptibility to TCUEAP1.

${ }^{b} \boldsymbol{P}$, clear spot could be seen; $\boldsymbol{N}$, no clear spot could be seen.

centrifugation for $2 \mathrm{~h}$ at 39,000 $\times g$ in a Beckman Avanti J-25I. The pellets were re-suspended in $1.0 \mathrm{ml}$ of TE buffer and purified by banding on the block gradient of $\mathrm{CsCl}$ representing 1.2, 1.3, and $1.4 \mathrm{~g} / \mathrm{cm}^{3}$ ( $2 \mathrm{ml}$ for each block) in ultracentrifugation. The ultracentrifugation conditions were $107,200 \times g$ for $3 \mathrm{~h}$ at $4^{\circ} \mathrm{C}$ with the SW41Ti rotor in a Beckman LE-80K. The phage band collected was dialyzed against the TE buffer and then stored at $4^{\circ} \mathrm{C}$ until further use.

\section{Transmission Electron Microscopy (TEM) of Phage Particles}

Phage morphology was examined by TEM with negatively stained preparations. A drop of purified phages with a titer of approximately $10^{10} \mathrm{PFU} / \mathrm{ml}$ was applied to the surface of a formvar-coated grid (200-mesh copper grids), followed by negative staining with $2 \%$ uranyl-acetate $(\mathrm{pH} 3)$. The phage morphology was examined by using a Hitachi H-7500 transmission electron microscope operated at $80 \mathrm{kV}$ (Hitachi Company, Japan).

\section{Phage DNA Preparation, Genome Sequencing, and Annotation}

DNA of the purified phage TCUEAP1 was prepared by extraction with phenol/chloroform and ethanol precipitation. The genome was sequenced by MiSeq (Illumina, Inc., San Diego, CA, United States). Raw reads were assembled using Bowtie (v1.1.1) (Langmead et al., 2009). The termini and package mode of the genome were analyzed by PhageTerm (Garneau et al., 2017).
Putative protein-encoding open reading frames (ORFs) on the resulting whole genome were predicted using the program Prodigal (Hyatt et al., 2010). The functions of the proteins were annotated by running NCBI protein $\mathrm{BLAST}^{1}$ against $n r$ database. Further annotations were helped by restricting the BLAST search to the organism virus (taxid 10239). The genomic sequence of phage TCUEAP1 has been submitted to NCBI (GenBank accession number MN732896).

\section{Determination of Optimal MOI}

Host strain E. anophelis ANO15 was grown in LB medium at $37^{\circ} \mathrm{C}$ to the early log phase $\left(10^{8} \mathrm{CFU} / \mathrm{ml}\right)$. Six different ratios of TCUEAP1 to the host strain were added to LB medium, for MOI 0.001, 0.01, 0.1, 1, 10, and 100 PFU/CFU. After $3.5 \mathrm{~h}$ of incubation at 25 or $37^{\circ} \mathrm{C}$, the samples were collected, and the titers of the phages were determined by serial dilution and the double-layer method (Adams, 1959). All experiments were performed in triplicate.

\section{In vitro Adsorption Assay}

The adsorption experiment was performed according to Adams (1959). When the growth of the host strain E. anophelis ANO15 and the control strain E. meningoseptica BCRC 10677 reached an $\mathrm{OD}_{600}$ of $1.0,2 \mathrm{ml}$ of each culture was harvested and fresh LB broth was added to a final volume of $20 \mathrm{ml}$. Phage stock of TCUEAP1 was added to each diluted culture at an MOI of 1 and

\footnotetext{
${ }^{1}$ http://www.ncbi.nlm.nih.gov/
} 
incubated at $25^{\circ} \mathrm{C}$ for $30 \mathrm{~min}$. Aliquots of $100-\mu 1$ samples were collected from 0 to $30 \mathrm{~min}$ at 5-min intervals, and centrifuged at $10,000 \mathrm{~g}$ for $10 \mathrm{~min}$. The supernatants containing the nonadsorbed phages were titrated by serial dilution and the doublelayer method. The percentage of free phages was calculated by dividing the phage titer in the supernatant to that in the initial phage stock. All experiments were performed in triplicate.

\section{One-Step Growth Curve}

The culture of the host strain was incubated to an $\mathrm{OD}_{600}$ of 1.0. Three-milliliter aliquots of the bacterial culture were mixed with the phage TCUEAP1 at an MOI of 1 , and the phages were allowed to adsorb to the host for $10 \mathrm{~min}$ at $25^{\circ} \mathrm{C}$. The mixture was centrifuged, and the supernatant was discarded to remove free phage particles. The pellets were re-suspended in $30 \mathrm{ml}$ of fresh $\mathrm{LB}$ broth and incubated at $25^{\circ} \mathrm{C}$. Two sets of the samples were collected every $10 \mathrm{~min}$, for $80 \mathrm{~min}$. One of the two samples was treated with $1 \%$ chloroform (final concentration) to release intracellular phages. Then, the sets of the samples were immediately titrated by serial dilution and the double-layer method. All experiments were performed in triplicate. The latent period, eclipse period, and burst size of TCUEAP1 were derived from the growth curve.

\section{Phage Infection Assay}

The culture of the host strain E. anophelis ANO15 was incubated to an $\mathrm{OD}_{600}$ of 0.5 and then was mixed with the phage TCUEAP1 at different MOIs (from 0.0001 to 10 ) at 25 or $37^{\circ} \mathrm{C}$. The control experiments were performed using equal volume of phage buffer [10 mM Tris- $\mathrm{HCl}$ (pH 7.5), $10 \mathrm{mM} \mathrm{MgSO}_{4}, 68.5 \mathrm{mM} \mathrm{NaCl}$, and $1 \mathrm{mM} \mathrm{CaCl}_{2}$ ] to replace the phage stock. The post-infection $\mathrm{OD}_{600}$ values were measured for $14 \mathrm{~h}$, at 30-min intervals for the first 7 or $8 \mathrm{~h}$.

\section{Host Range Analysis}

The host range of TCUEAP1 was examined by both the doublelayer method (Adams, 1959) and the spot test (Romig and Brodetsky, 1961) on the 20 Elizabethkingia spp. used to screen phages from the water samples (Table 1). The bacterial strains were separately cultured to reach an $\mathrm{OD}_{600}$ of 1 . For the doublelayer method, $100 \mu \mathrm{l}$ of 10 -fold serially diluted $\left(10^{1}\right.$ to $\left.10^{9}\right)$ phage stock was mixed with $100 \mu \mathrm{l}$ of the bacterial culture and $5 \mathrm{ml}$ of soft LB agar (0.7\%) and then poured over the solid LB agar plates. Plates were incubated overnight at $25^{\circ} \mathrm{C}$. For the spot test, $100 \mu \mathrm{l}$ of the bacterial culture was included in the top agar of the doublelayered agar plates, and $10 \mu \mathrm{l}$ of phage-containing solution $\left(10^{5}\right.$ PFU) was spotted onto the bacterial lawns. Plates were dried in a laminar flow hood for $10 \mathrm{~min}$ and incubated at $25^{\circ} \mathrm{C}$ for 18 to $20 \mathrm{~h}$. The observation of plaques on the bacterial lawn was recorded. Each test was repeated three times.

\section{Effect of Temperature and $\mathrm{pH}$ on TCUEAP1 Stability}

Thermal and $\mathrm{pH}$ stability tests were carried out using the doublelayer method (Adams, 1959). In the thermal stability tests, aliquots of phage TCUEAP1 preparations $\left(10^{9} \mathrm{CFU} / \mathrm{ml}\right)$ were treated at pH 7 and different temperatures $(4,25,37,50,60$, and $70^{\circ} \mathrm{C}$ ) in distilled water for $1 \mathrm{~h}$. For the $\mathrm{pH}$ stability experiments, phage preparations were treated with various $\mathrm{pH}$ buffers $(\mathrm{pH} 2$, 4,7 , and 11 ) at $25^{\circ} \mathrm{C}$ in distilled water for $1 \mathrm{~h}$. The number of the remaining infective phages was determined by the double-layer method at $25^{\circ} \mathrm{C}$.

\section{Phage Therapy in the Mouse Sepsis Model}

To evaluate the ability of phage TCUEAP1 to control the bacterial load and prevent lethal bacteremia, three experimental conditions were tested. Thirty eight-week-old male BALB/c mice (provided by NLAC Company, Taiwan) were randomly assigned to three groups ( $n=10$ per group). E. anophelis ANO15 was grown in $\mathrm{LB}$ broth at $37^{\circ} \mathrm{C}$ for $18 \mathrm{~h}$ and adjusted to the appropriate concentration $\left(1 \times 10^{10} \mathrm{CFU} / \mathrm{ml}\right)$ in normal saline $(0.9 \% \mathrm{NaCl})$. The first group was only inoculated intraperitoneally with $100 \mu \mathrm{l}$ of normal saline and phage TCUEAP1 $\left(1 \times 10^{9} \mathrm{PFU} / \mathrm{mouse}, 100 \mu \mathrm{l} / \mathrm{mouse}\right)$ to assess the phage toxicity to mice. The remaining two groups were inoculated intraperitoneally with $1 \times 10^{9} \mathrm{CFU}$ of E. anophelis ANO15 $\left(1 \times 10^{9} \mathrm{CFU} / \mathrm{mouse}, 100 \mu \mathrm{l} /\right.$ mouse $)$, and $2 \mathrm{~h}$ later, intraperitoneal administration with either phage TCUEAP1 $\left(1 \times 10^{9} \mathrm{PFU} / \mathrm{mouse}, 100 \mu \mathrm{l} /\right.$ mouse $)$ or $100 \mu \mathrm{l}$ of normal saline. After $6 \mathrm{~h}$ post-infection, seven mice were randomly selected from each of the two groups and $50 \mu \mathrm{l}$ of blood was taken by tail vein sampling to evaluate the bacterial load. The animals were monitored for 7 days and the survival rate of each group was calculated.

\section{Statistical Analysis}

Data are expressed as the mean \pm standard deviation. The statistical significance of all the data was analyzed with the Student's $t$-test. Statistical significance was defined as $p<0.05$. Statistical analysis of the mouse survival rate evaluations was performed using GraphPad Prism software 6.0 with $p<0.05$.

\section{Ethics Statement}

All experiments involving the mice and all the care and handling of the mice were performed using protocols approved by the Institutional Animal Care and Use Committee of Tzu Chi University (No. 107083). All methods were performed under the relevant guidelines.

\section{RESULTS}

\section{Isolation of a New Phage for E. anophelis}

Dozens of wastewater samples around Hualien Tzu Chi hospital were collected and screened by the double-layer method using 20 strains of Elizabethkingia spp. One obtained phage that formed clear and haloed round plaques of about 1-2 $\mathrm{mm}$ in diameter (Figure 1A) on E. anophelis ANO15 was designated as TCUEAP1. TEM showed that TCUEAP1 possessed an icosahedral head with a diameter of approximately $47 \pm 3 \mathrm{~nm}$, and a tail that was $172 \pm 3 \mathrm{~nm}$ long and $12 \pm 1 \mathrm{~nm}$ in diameter 


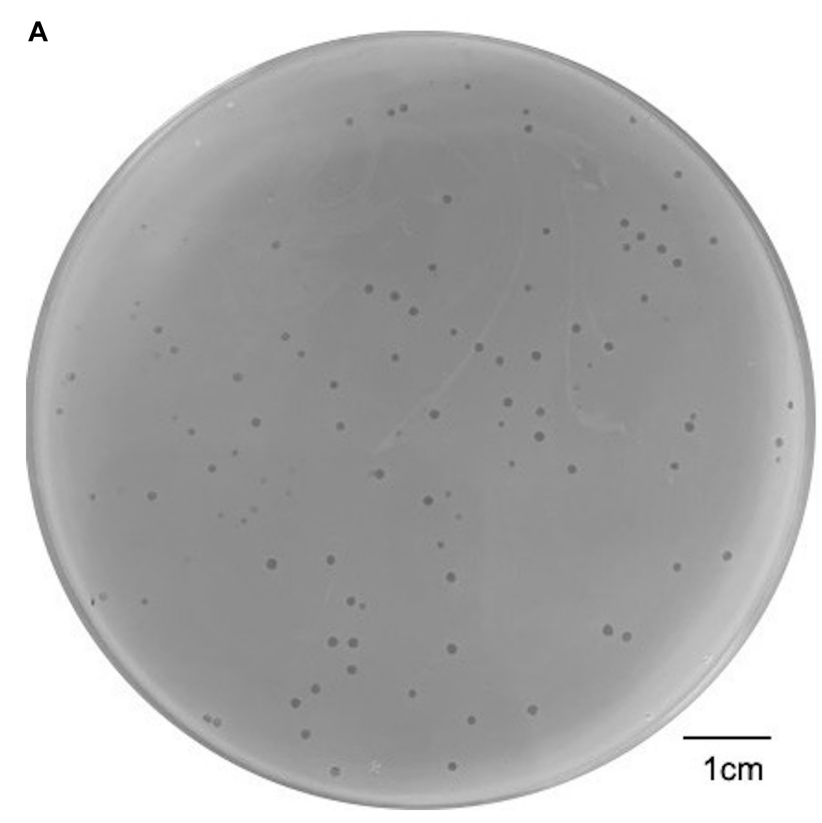

B

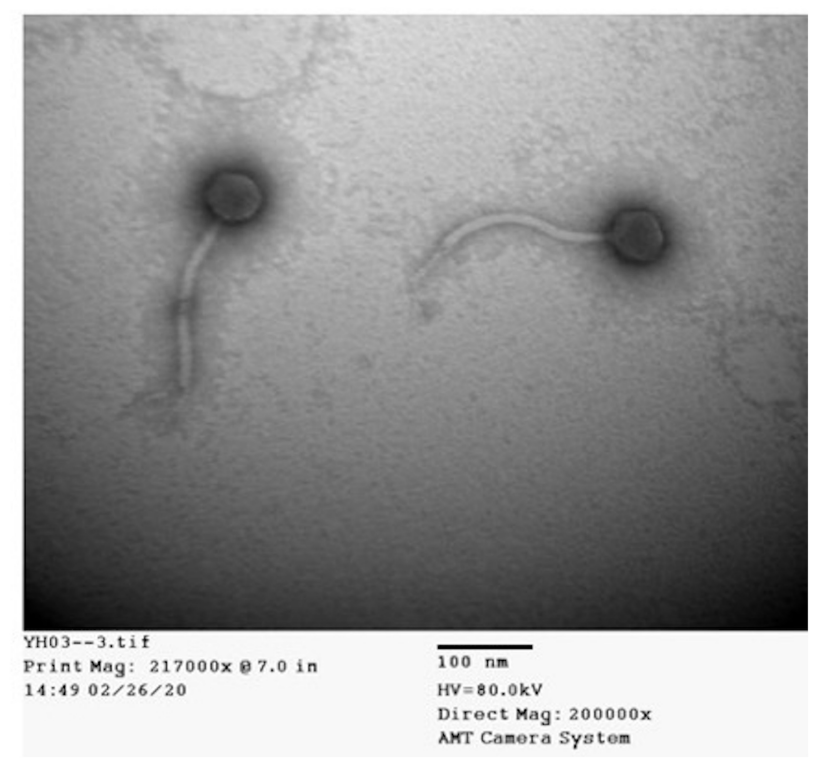

FIGURE 1 | Plaque and transmission electron microscopic (TEM) image of phage TCUEAP1. (A) Plaques formed by phage TCUEAP1. Scale bar: 1 cm. (B) Morphology of phage TCUEAP1 revealed under TEM. Scale bar: $100 \mathrm{~nm}$.

(Figure 1B). The morphology suggested that TCUEAP1 could be assigned to the order Caudovirales and family Siphoviridae.

\section{Optimal MOI of Phage TCUEAP1}

We tested the MOI ranging from 0.001 to 100 to determine the optimal values for producing maximal phage titers at 25 and $37^{\circ} \mathrm{C}$ (Figure 2). The results showed that at both temperatures, the optimal MOI was 1 , at which the phage titer at $25^{\circ} \mathrm{C}$ (about $10^{11}$ $\mathrm{PFU} / \mathrm{ml}$ ) was even higher than at $37^{\circ} \mathrm{C}$ (about $10^{10} \mathrm{PFU} / \mathrm{ml}$ ). This MOI was used for the following experiments.

\section{Biological Characterization of TCUEAP1}

The adsorption experiment performed at an MOI of 1 at $25^{\circ} \mathrm{C}$ showed that approximately $70 \%$ of the phage particles of TCUEAP1 were adsorbed to the host E. anophelis ANO15 within $20 \mathrm{~min}$ of incubation, and no significant rise was observed as the incubation time increased further (Figure 3A). To characterize the infection process of the phage, the one-step growth curve of TCUEAP1 on E. anophelis ANO15 at an MOI of 1 at $25^{\circ} \mathrm{C}$ was determined.

The growth curves revealed that the eclipse and latent period of TCUEAP1 were around 30 and $40 \mathrm{~min}$, respectively. The rise period lasted for about $20 \mathrm{~min}$, and released a small burst size of about 10 PFU per infected cell (Figure 3B). The stability of phage TCUEAP1 at varying temperatures and $\mathrm{pH}$ conditions was also investigated. TCUEAP1 phages showed their viability at the tested temperature from 4 to $50^{\circ} \mathrm{C}$, maximally at 25 and $37^{\circ} \mathrm{C}$, and were quickly inactivated when heated to $60^{\circ} \mathrm{C}$ (Figure $3 \mathrm{C}$ ). At pH 7 and 11, phage TCUEAP1 survived generally well, while no titer was recorded at a $\mathrm{pH}$ of 2 and 4 (Figure 3D).

\section{Host Specificity and Host Growth Inhibition of TCUEAP1}

To evaluate the host specificity of TCUEAP1, phage lysates were tested using the double-layer method and the spot test against 20 strains of Elizabethkingia species listed in Table 1. None of them share the same pulsotypes. The results of the double-layer method indicated that TCUEAP1 could only form plaques against three strains of E. anophelis, including the host strain E. anophelis ANO15. In contrast, the results of the spot test showed that TCUEAP1 solution was able to form clear spots on 16 isolates of Elizabethkingia spp., including one E. meningoseptica strain (Table 1). The infection assays of phage TCUEAP1 against E. anophelis ANO15 at 25 and $37^{\circ} \mathrm{C}$ were performed in vitro. The results (Figure 4) showed that at $25^{\circ} \mathrm{C}$, even at MOI 0.001 , phage TCUEAP1 could effectively reduce the growth of $E$. anophelis ANO15. In contrast, the results at $37^{\circ} \mathrm{C}$ showed that when the MOI was under 0.01 , TCUEAP1 had no observable effect on the growth of the host.

\section{Sequencing and Bioinformatics Analysis of TCUEAP1 Genomic DNA}

Raw reads of the genome of TCUEAP1 were assembled into a circularly permutated form. By detecting the biases in the number of sequence reads, PhageTerm (Garneau et al., 2017) software predicted the genome to be a concatemeric DNA packaged through a headful packaging mechanism. The resulting genome of TCUEAP1 is a double-stranded linear DNA with a length of 49,816 bp and GC content of $39.34 \%$. It was predicted by Prodigal (Hyatt et al., 2010) to contain 73 ORFs, all located on the positive strand. No tRNA genes were detected by the tRNAscanSE 2.0 web server. Through the protein BLAST analysis, only 
A

$25^{\circ} \mathrm{C}$

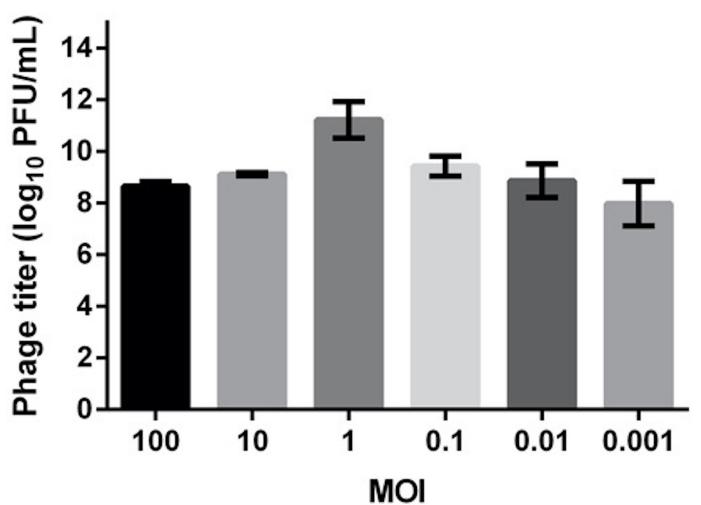

B

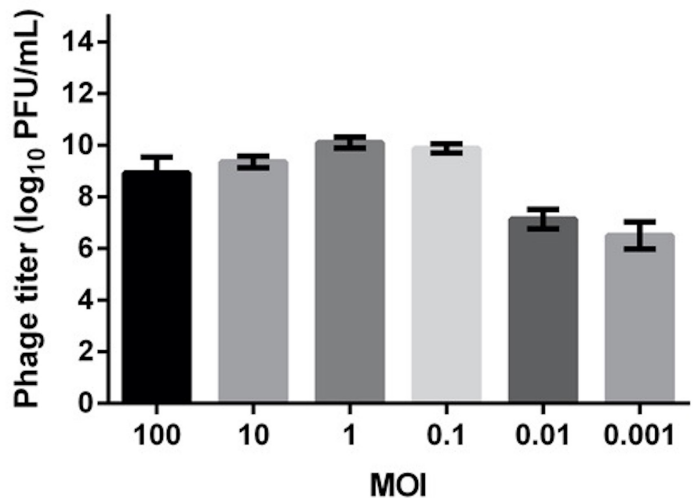

FIGURE 2 | Determination of the optimal multiplicity of infection (MOI) for TCUEAP1. Comparison of the phage titers after $3.5 \mathrm{~h}$ of incubation at six MOI values $(0.001,0.01,0.1,1,10$, and $100 \mathrm{PFU} / \mathrm{CFU})$ at $25^{\circ} \mathrm{C}(\mathbf{A})$ and $37^{\circ} \mathrm{C}(\mathbf{B})$. The experiments were repeated three times.

A

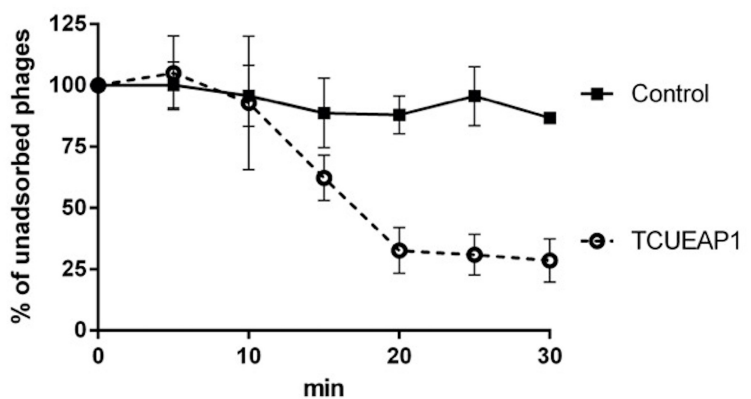

C

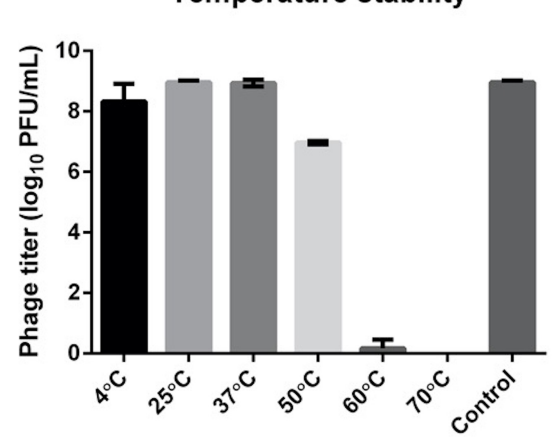

B

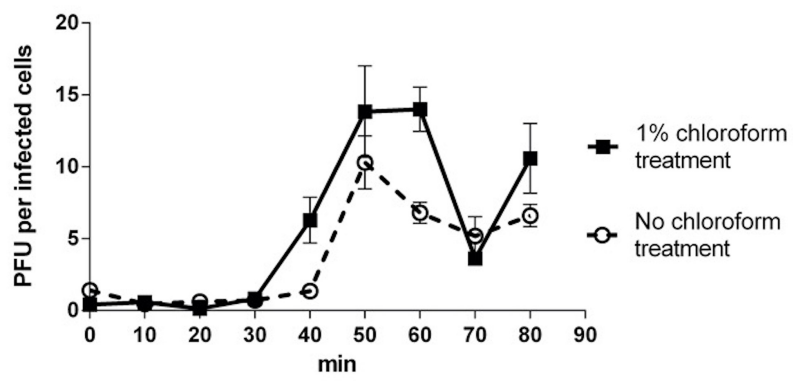

D

pH stability

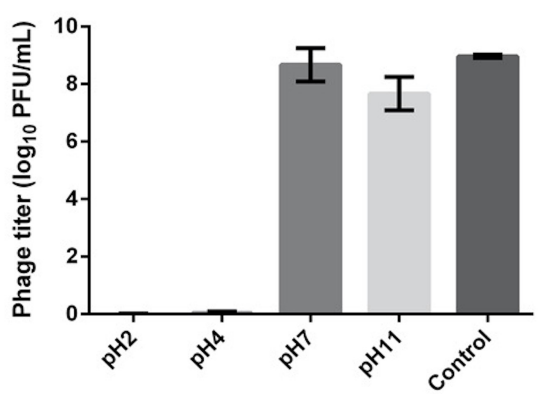

FIGURE 3 | Characterization of TCUEAP1. (A) Adsorption curve of the phage TCUEAP1 to the host E. anophelis ANO15 and the control E. meningoseptica BCRC 10677 at an $\mathrm{MOI}$ of 1 at $25^{\circ} \mathrm{C}$. Aliquots were taken at intervals of $5 \mathrm{~min}$ (up to $30 \mathrm{~min}$ ), and the supernatant containing the non-adsorbed phages were titrated. Percentage unadsorbed phages is the ratio of the phage titer in the supernatant to that in the initial phage stock. (B) One-step growth curve of the phage TCUEAP1 on E. anophelis ANO15 at $25^{\circ} \mathrm{C}$. PFU per infected cells in chloroform-treated and chloroform-untreated cultures are shown at different time points. (C) The effect of temperature. TCUEAP1 was incubated at different temperature values for $1 \mathrm{~h}$ before determining the phage titer. (D) The effect of pH on TCUEAP1. TCUEAP1 was incubated at different $\mathrm{pH}$ values for $1 \mathrm{~h}$ before determining the phage titer. All experiments were repeated three times.

putative products from 21 ORFs could find statistically significant $(E<0.001)$ matches, of which six only matched to hypothetical proteins in the databases. The annotations adopted in this paper were based on the BLAST search against the proteins of virus (taxid) origins (Supplementary Table S1). Overall, annotations (Figure 5) showed that the ORFs predicted to 
A

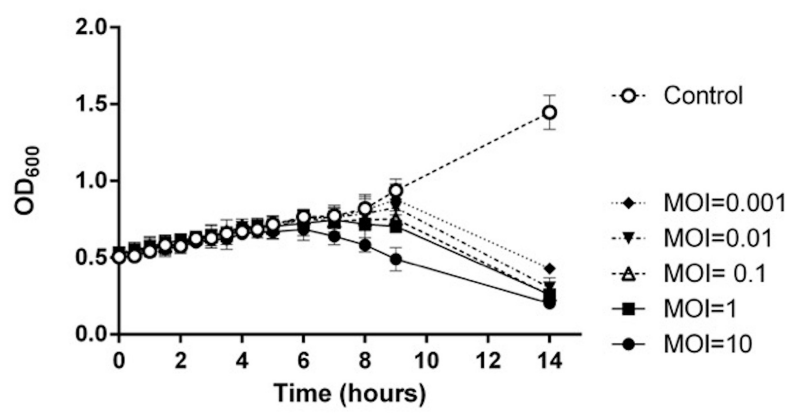

B

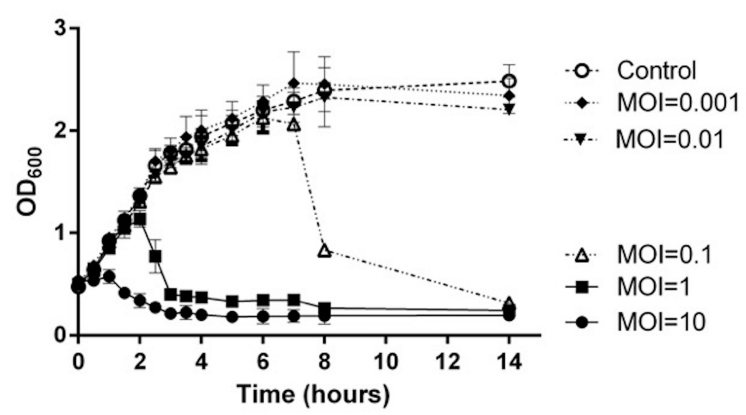

FIGURE 4 | The infection assay of the phage TCUEAP1 against $E$. anophelis ANO15 in vitro at $25^{\circ} \mathrm{C}$ (A) and $37^{\circ} \mathrm{C}$ (B). E. anophelis ANO15 was infected by the phage TCUEAP1 at MOI values of 10, 1, 0.1, 0.01, or 0.001 , and cultured for $14 \mathrm{~h}$. The control experiments were performed using equal volumes of phage buffer. This experiment was repeated three times.

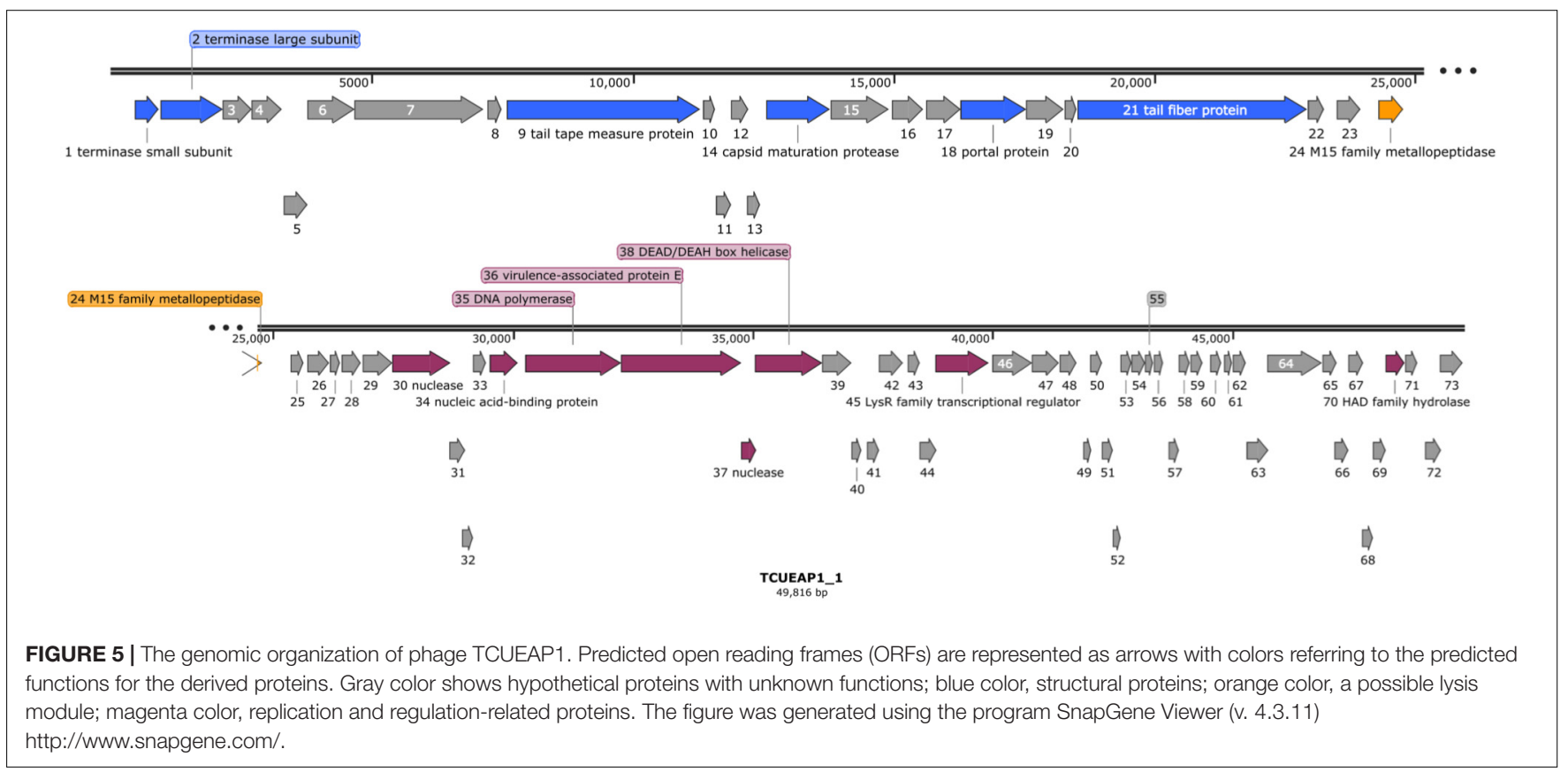

encode structural products were located in the upstream genomic cluster, and the ORFs related to replication and regulation were in the downstream genomic cluster. ORF 24 between the two clusters encodes a putative product containing the M15 metallopeptidase domain, a functional module related to phage endolysin (Mikoulinskaia et al., 2009). No lysogenic characteristics, such as integration-related or CI repressor genes were identified.

\section{Phage Therapy in the Mouse Sepsis Model}

Since lethal bacteremia is a common outcome of E. anophelis infection, we investigated the ability of phage TCUEAP1 to rescue mice from lethal sepsis induced by intraperitoneal injection of E. anophelis. The minimum lethal dose of E. anopheles to BALB/c mice was determined to be $1 \times 10^{9} \mathrm{CFU} /$ mouse (Supplementary Figure S1). To assess the biosafety of phage TCUEAP1, 10 mice were inoculated intraperitoneally with phage TCUEAP1 $\left(1 \times 10^{9}\right.$ $\mathrm{PFU} / \mathrm{mouse}$ ) and monitored for 7 days. The results showed that all mice in the control group had normal vital signs and survived the 7 days of observation period (Figure 6A). Each mouse received $10^{9} \mathrm{CFU}$ of $E$. anophelis intraperitoneally, and was treated $2 \mathrm{~h}$ later with a single dose of $10^{9}$ PFU of phage TCUEAP 1 or normal saline by the same route. While $70 \%$ of normal salinetreated mice died within 1 day, the phage TCUEAP1-treated mice had a significantly higher rate of survival, with $80 \%$ being rescued from the lethal dose of E. anophelis (Figure 6A). To quantify the ability of phage TCUEAP1 to reduce E. anophelis load in vivo, after $6 \mathrm{~h}$ post-E. anophelis infection, seven mice were randomly selected from each of the two groups to measure the bacterial load in the blood. There was approximately $5 \times 10^{5} \mathrm{CFU} / \mathrm{ml}$ of bacteria in the blood from the normal saline-treated mice (Figure 6B). In contrast, the bacterial load in the blood collected from the mice treated with phage TCUEAP1 was reduced at 

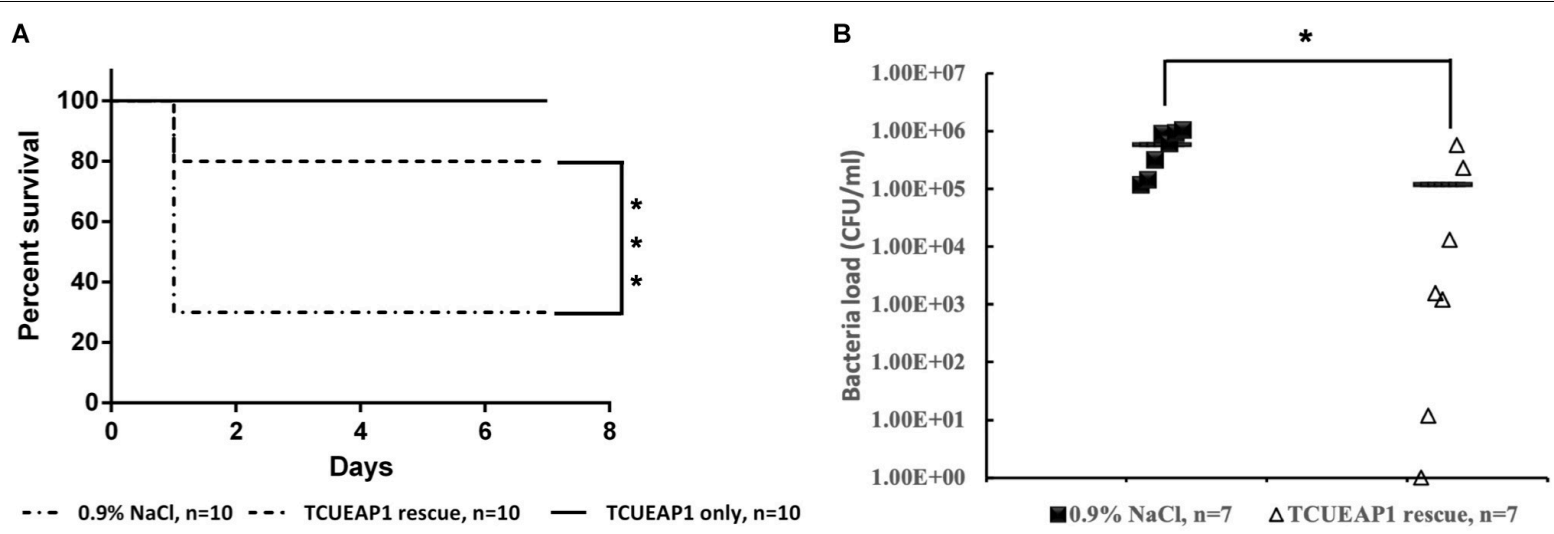

FIGURE 6 | Therapeutic efficacy of phage TCUEAP1 against mice with sepsis induced by $E$. anophelis infection. (A) The survival of the mice treated with a single dose of phage TCUEAP1 or normal saline intraperitoneally after $E$. anophelis infection. The survival of the mice was monitored for 7 days. ${ }^{\star \star *} p<0.001$ for normal saline versus phage TCUEAP1. (B) Blood samples of mice treated with normal saline (solid square) versus those of mice treated with phage TCUEAP1 (open triangle) at $6 \mathrm{~h}$ after bacterial inoculation. The line indicates mean bacterial load; ${ }^{\star} \mathrm{p}<0.05$ for normal saline versus phage TCUEAP1.

least fivefold $(p<0.05)$, to the level about $1 \times 10^{5} \mathrm{CFU} / \mathrm{ml}$. These results collectively indicate that phage TCUEAP1 has good antimicrobial activity in vivo.

\section{DISCUSSION}

As more studies have employed advanced species-identification methods, the clinical importance of $E$. anophelis has begun to emerge, having been identified as a novel human pathogen in just a few years (Janda and Lopez, 2017). The rising trend of drug resistance among bacterial pathogens prompts a consideration of phage therapy (Gorski et al., 2018; Caflisch and Patel, 2019). Among the flourish of various phage studies, there is no discussion of use against the novel pathogen Elizabethkingia. In this work, from dozens of wastewater samples, we isolated TCUEAP1, the virulent phage infecting E. anophelis. Characterization and genome analysis of TCUEAP1 were performed.

The stability studies showed that the phage could not resist high temperatures (above $60^{\circ} \mathrm{C}$ ) and was very sensitive to an acidic environment ( $\mathrm{pH} 2$ and $\mathrm{pH} 4)$. The specificity test using 20 bacterial strains showed that while TCUEAP1 could only infect three strains, the phage lysate had a broad lytic spectrum against 16 strains. The difference may imply the possible existence of phage-encoded products, such as endolysin and hydrolase in the phage lysates. The adsorption rate of TCUEAP1 to the host bacteria could reach $70 \%$ in $20 \mathrm{~min}$, but then appeared to encounter a limit and did not change much after further $10 \mathrm{~min}$. As stated earlier, in the optimal MOI and infection assays of TCUEAP1 at 25 and $37^{\circ} \mathrm{C}$, TCUEAP1 propagated better at $25^{\circ} \mathrm{C}$, and could reduce the growth of the host bacteria even when the MOI was as low as 0.001 . This matched our experience when we tried to isolate the phages targeting Elizabethkingia from the environment. We found it helpful to perform the co-culture of TCUEAP1 with its host at $25^{\circ} \mathrm{C}$ to slow down the bacterial growth rate and allow the phage to propagate to a suitable amount.
The genome of phage TCUEAP1 was sequenced and analyzed. For more than $70 \%$ (52 out of 73 ) of possible proteins derived from the TCUEAP1 genome, we could not identify any homologs using BLAST searches. Also, as we tried to identify the evolutionary related phages of TCUEAP1, among the 73 putative protein products, maximally only seven of them (mainly products of ORF 34 to 38) could find possible homologs from a single phage origin by BLAST. This patchy sequence similarity means that the traditional linear phylogenetic relationship is not suitable for TCUEAP1. We then tried to use vConTACT2 (v0.9.15) to assign the taxonomic status of TCUEAP1. vConTACT2 is a network-based application using phage genomes and their protein content for phage classification (Bin Jang et al., 2019). This type of program was regarded to be more suitable for the highly mosaic phenomenon seen on phage genomes (Dion et al., 2020). The analysis indicated TCUEAP1 to be a "singleton" virus, meaning no close relatives could be identified in the phage genome database (ProkaryoticViralRefSeq97-Merged). This means that more viral genome space needs to be sampled to build up the connections of TCUEAP1 to other phages.

The putative product of ORF36 was suggested to be a virulence-associated protein E (vapE) in BLAST results. Apart from one report showing that, in the bacterial pathogen of swine, deleting the vapE gene reduced the bacterial pathogenesis in mice (Ji et al., 2016), no details about the nature of the virulence have been identified so far. Among the BLAST results, there were a few protein hits for the predicted product of ORF36 being annotated as DNA primase (Supplementary Table S1), revealing another possible function for the predicted ORF36.

Endolysin, also termed phage lysin, is the protein encoded by phages to degrade the peptidoglycan of bacteria. It has been suggested to be a potent antibacterial agent separately from the entire phage (Lai et al., 2011). The potential product of ORF24 in the TCUEAP1 genome was identified to contain the M15 family peptidase domain, implying its possible connection to endolysin function. This presumption is currently under investigation. 
When applied to the mice with sepsis induced by E. anophelis, TCUEAP1 was able to decrease the bacterial load by over fivefold and enhanced mice survival. Considering the new clinical challenges from Elizabethkingia, we believe that the isolation and characterization of the world's first phage against Elizabethkingia is valuable. It not only provides a way to understand the Elizabethkingia bacteria but can also further the preparation of weapons to combat Elizabethkingia infections in the future.

\section{DATA AVAILABILITY STATEMENT}

The datasets generated for this study can be found in the GenBank accession number MN732896.

\section{ETHICS STATEMENT}

The animal study was reviewed and approved by Institutional Animal Care and Use Committee of Tzu Chi University (No. 107083).

\section{AUTHOR CONTRIBUTIONS}

K-CC conceived and guided this project. K-CC and M-JL analyzed the results and wrote the manuscript. S-YP, L-KC, PP,

\section{REFERENCES}

Abedon, S. T., Garcia, P., Mullany, P., and Aminov, R. (2017). Editorial: phage therapy: past. Present and future. Front. Microbiol. 8:981. doi: 10.3389/fmicb. 2017.00981

Adams, M. H. (1959). Bacteriophages. New York, NY: Interscience Publishers.

Bin Jang, H., Bolduc, B., Zablocki, O., Kuhn, J. H., Roux, S., Adriaenssens, E. M., et al. (2019). Taxonomic assignment of uncultivated prokaryotic virus genomes is enabled by gene-sharing networks. Nat. Biotechnol. 37, 632-639. doi: 10.1038/ s41587-019-0100-8

Caflisch, K. M., and Patel, R. (2019). Implications of bacteriophageand bacteriophage component-based therapies for the clinical microbiology laboratory. J. Clin. Microbiol. 57:00229-19. doi: 10.1128/JCM. 00229-19

Chang, Y. C., Lo, H. H., Hsieh, H. Y., and Chang, S. M. (2014). Identification and epidemiological relatedness of clinical Elizabethkingia meningoseptica isolates from central Taiwan. J. Microbiol. Immunol. Infect. 47, 318-323. doi: 10.1016/j. jmii.2013.03.007

Cheng, Y. H., Perng, C. L., Jian, M. J., Cheng, Y. H., Lee, S. Y., Sun, J. R., et al. (2019). Multicentre study evaluating matrix-assisted laser desorption ionization-time of flight mass spectrometry for identification of clinically isolated Elizabethkingia species and analysis of antimicrobial susceptibility. Clin. Microbiol. Infect. 25, 340-345. doi: 10.1016/j.cmi.2018.04.015

Chew, K. L., Cheng, B., Lin, R. T. P., and Teo, J. W. P. (2018). Elizabethkingia anophelis Is the dominant Elizabethkingia species found in blood cultures in Singapore. J. Clin. Microbiol. 56:e01445-17. doi: 10.1128/JCM. 01445-17

Coyle, A. L. (2017). Elizabethkingia anophelis: exploring the outbreak of disease in the Midwest. Nursing 47, 61-63. doi: 10.1097/01.NURSE.0000512887.67622.84

Dedrick, R. M., Guerrero-Bustamante, C. A., Garlena, R. A., Russell, D. A., Ford, K., Harris, K., et al. (2019). Engineered bacteriophages for treatment of a patient with a disseminated drug-resistant Mycobacterium abscessus. Nat. Med. 25, 730-733. doi: 10.1038/s41591-019-0437-z

Dion, M. B., Oechslin, F., and Moineau, S. (2020). Phage diversity, genomics and phylogeny. Nat. Rev. Microbiol. 18, 125-138. doi: 10.1038/s41579-019-0311-5
P-WY, and Y-ZL performed the characterization of the phage TCUEAP1. S-YP and W-JW performed the animal studies. All authors reviewed the manuscript.

\section{FUNDING}

This work was supported partly by grants (contract number TCRPP107005) from Tzu Chi University and partly by the grants 106-2320-B-320-008-MY2 and 108-2320-B-320007-MY2 from the Ministry of Science and Technology of Taiwan.

\section{ACKNOWLEDGMENTS}

We thank the Electron Microscopy Laboratory of the Department of Anatomy of Tzu Chi University for technical assistance.

\section{SUPPLEMENTARY MATERIAL}

The Supplementary Material for this article can be found online at: https://www.frontiersin.org/articles/10.3389/fmicb. 2020.00728/full\#supplementary-material

Frank, T., Gody, J. C., Nguyen, L. B., Berthet, N., Le Fleche-Mateos, A., Bata, P., et al. (2013). First case of Elizabethkingia anophelis meningitis in the Central African Republic. Lancet 381:1876. doi: 10.1016/S0140-6736(13)60318-9

Garneau, J. R., Depardieu, F., Fortier, L. C., Bikard, D., and Monot, M. (2017). PhageTerm: a tool for fast and accurate determination of phage termini and packaging mechanism using next-generation sequencing data. Sci. Rep. 7:8292. doi: 10.1038/s41598-017-07910-5

Gorski, A., Miedzybrodzki, R., Lobocka, M., Glowacka-Rutkowska, A., Bednarek, A., Borysowski, J., et al. (2018). Phage therapy: what have we learned? Viruses 10:288.

Han, M. S., Kim, H., Lee, Y., Kim, M., Ku, N. S., Choi, J. Y., et al. (2017). Relative prevalence and antimicrobial susceptibility of clinical isolates of Elizabethkingia species based on 16S rRNA gene sequencing. J. Clin. Microbiol. 55, 274-280. doi: 10.1128/JCM.01637-16

Hyatt, D., Chen, G. L., Locascio, P. F., Land, M. L., Larimer, F. W., and Hauser, L. J. (2010). Prodigal: prokaryotic gene recognition and translation initiation site identification. BMC Bioinformatics 11:119. doi: 10.1186/1471-2105-11-119

Janda, J. M., and Lopez, D. L. (2017). Mini review: new pathogen profiles: Elizabethkingia anophelis. Diagn. Microbiol. Infect. Dis. 88, 201-205. doi: 10. 1016/j.diagmicrobio.2017.03.007

Ji, X., Sun, Y., Liu, J., Zhu, L., Guo, X., Lang, X., et al. (2016). A novel virulenceassociated protein, vapE, in Streptococcus suis serotype 2. Mol. Med. Rep. 13, 2871-2877. doi: 10.3892/mmr.2016.4818

Kim, K. K., Kim, M. K., Lim, J. H., Park, H. Y., and Lee, S. T. (2005). Transfer of Chryseobacterium meningosepticum and Chryseobacterium miricola to Elizabethkingia gen. nov. as Elizabethkingia meningoseptica comb. nov. and Elizabethkingia miricola comb. nov. Int. J. Syst. Evol. Microbiol. 55, 1287-1293. doi: 10.1099/ijs.0.63541-0

King, E. O. (1959). Studies on a group of previously unclassified bacteria associated with meningitis in infants. Am. J. Clin. Pathol. 31, 241-247. doi: 10.1093/ajcp/ 31.3.241

Lai, M. J., Lin, N. T., Hu, A., Soo, P. C., Chen, L. K., Chen, L. H., et al. (2011). Antibacterial activity of Acinetobacter baumannii phage varphiAB2 endolysin (LysAB2) against both gram-positive and gram-negative bacteria. Appl. Microbiol. Biotechnol. 90, 529-539. doi: 10.1007/s00253-011-3104-y 
Langmead, B., Trapnell, C., Pop, M., and Salzberg, S. L. (2009). Ultrafast and memory-efficient alignment of short DNA sequences to the human genome. Genome Biol. 10, R25. doi: 10.1186/gb-2009-10-3-r25

Lau, S. K., Chow, W. N., Foo, C. H., Curreem, S. O., Lo, G. C., Teng, J. L., et al. (2016). Elizabethkingia anophelis bacteremia is associated with clinically significant infections and high mortality. Sci. Rep. 6:26045. doi: 10.1038/ srep 26045

Lin, J. N., Lai, C. H., Yang, C. H., and Huang, Y. H. (2018). Comparison of clinical manifestations, antimicrobial susceptibility patterns, and mutations of fluoroquinolone target genes between Elizabethkingia meningoseptica and Elizabethkingia anophelis Isolated in Taiwan. J. Clin. Med. 7:538.

Lin, J. N., Lai, C. H., Yang, C. H., and Huang, Y. H. (2019). Elizabethkingia infections in humans: from genomics to clinics. Microorganisms 7:295. doi: 10.3390/microorganisms7090295

Merril, C. R., Scholl, D., and Adhya, S. L. (2003). The prospect for bacteriophage therapy in western medicine. Nat. Rev. Drug. Discov. 2, 489-497. doi: 10.1038/ nrd1111

Mikoulinskaia, G. V., Odinokova, I. V., Zimin, A. A., Lysanskaya, V. Y., Feofanov, S. A., and Stepnaya, O. A. (2009). Identification and characterization of the metal ion-dependent L-alanoyl-D-glutamate peptidase encoded by bacteriophage T5. FEBS J. 276, 7329-7342. doi: 10.1111/j.1742-4658.2009. 07443.x

Perrin, A., Larsonneur, E., Nicholson, A. C., Edwards, D. J., Gundlach, K. M., Whitney, A. M., et al. (2017). Evolutionary dynamics and genomic features of the Elizabethkingia anophelis 2015 to 2016 Wisconsin outbreak strain. Nat. Commun. 8:15483. doi: 10.1038/ncomms15483

Romig, W. R., and Brodetsky, A. M. (1961). Isolation and preliminary characterization of bacteriophages for Bacillus subtilis. J. Bacteriol. 82, 135-141.
Schooley, R. T., Biswas, B., Gill, J. J., Hernandez-Morales, A., Lancaster, J., Lessor, L., et al. (2017). Development and use of personalized bacteriophagebased therapeutic cocktails to treat a patient with a disseminated resistant Acinetobacter baumannii infection. Antimicrob. Agents. Chemother. 61:e0095417. doi: 10.1128/AAC.02221-18

Teo, J., Tan, S. Y., Tay, M., Ding, Y., Kjelleberg, S., Givskov, M., et al. (2013). First case of E. anophelis outbreak in an intensive-care unit. Lancet 382, 855-856. doi: 10.1016/S0140-6736(13)61858-9

Vandamme, P., Bernardet, J. F., Segers, P., Kersters, K., and Holmes, B. (1994). NOTES: new perspectives in the classification of the flavobacteria: description of Chryseobacterium gen. nov., Bergeyella gen. nov., and Empedobacter nom. rev. Int. J. Syst. Bacteriol. 44, 827-831.

Wittebole, X., De Roock, S., and Opal, S. M. (2014). A historical overview of bacteriophage therapy as an alternative to antibiotics for the treatment of bacterial pathogens. Virulence 5, 226-235. doi: 10.4161/viru. 25991

Conflict of Interest: The authors declare that the research was conducted in the absence of any commercial or financial relationships that could be construed as a potential conflict of interest.

Copyright (C) 2020 Peng, Chen, Wu, Paramita, Yang, Li, Lai and Chang. This is an open-access article distributed under the terms of the Creative Commons Attribution License (CC BY). The use, distribution or reproduction in other forums is permitted, provided the original author(s) and the copyright owner(s) are credited and that the original publication in this journal is cited, in accordance with accepted academic practice. No use, distribution or reproduction is permitted which does not comply with these terms. 